\title{
Usage of $\alpha$-picoline borane for the reductive amination of carbohydrates
}

\author{
Vanina A. Cosenza, Diego A. Navarro and Carlos A. Stortz* \\ Departamento de Química Orgánica-CIHIDECAR, Facultad de Ciencias Exactas y Naturales, \\ Universidad de Buenos Aires, Ciudad Universitaria, 3er piso, 1428 Buenos Aires, Argentina \\ E-mail: stortz@go.fcen.uba.ar \\ This article is dedicated to Profs. Rita H. Rossi, Julio C. Podestá, Manuel González Sierra \\ and Oscar S. Giordano, to recognize their achievements in organic chemistry and their \\ contributions in the development of the field in Argentina
}

\begin{abstract}
The reaction of reductive amination, widely used for carbohydrates, was reviewed in our lab, especially in the context of the analytical determination of carbohydrate enantiomers. The best conditions for the technique have been evaluated, showing that under optimal working conditions it is possible to use $\alpha$-picoline borane as a reducing agent instead of sodium cyanoborohydride without affecting the selectivity or the yield. The main reason for the variation of the technique was that, in the presence of acetic acid, secondary epimeric products were produced with $\alpha$-picoline borane due to an Amadori rearrangement. This new modification assures lower toxicity, and thus a more environmental-friendly reaction system. Preparative scale synthesis can also be efficiently made with this reducing reagent.
\end{abstract}

Keywords: Carbohydrates - Reductive Amination - Picoline borane - Amadori rearrangement

\section{Introduction}

The reaction of reductive amination, widely used for organic synthesis, allows for the conversion of the carbonyl group into amines. The reaction begins with the coupling of an aldehyde or ketone and a primary or secondary amine to give an imine, which is then reduced to give a secondary or tertiary amine ${ }^{1,2}$ (Scheme 1$)$. 


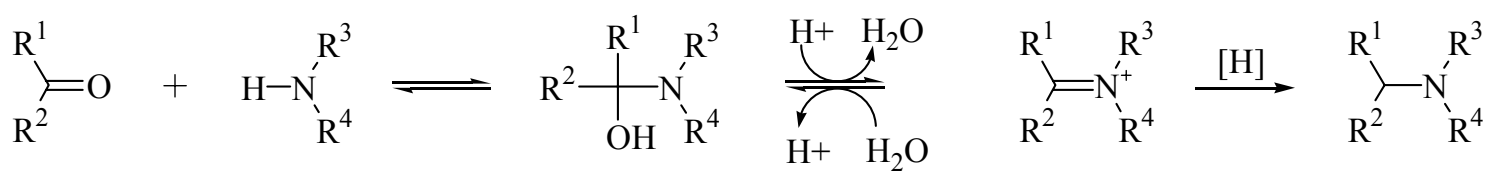

Scheme 1. Reductive amination reaction.

The reaction can be carried out either in a "one-pot" system, where the formation of the imine and its reduction product occur in only one operational stage, or stepwise, where the intermediate imine is isolated, and reduced in a second stage.

The selection of reducing agents in this type of reactions is critical, since they must reduce selectively the imine without affecting significantly the original carbonyl compound or other reducible groups present. A large number of reducing agents have been developed, though many of them present unwanted properties in terms of selectivity, secondary reactions, reaction conditions, safety hazards, and toxicity.

The catalytic hydrogenation is the most employed reductant for imines in large scale syntheses, ${ }^{3}$ although it is limited to molecules which do not carry double bonds or other reducible groups under hydrogenation conditions. For laboratory scale, sodium cyanoborohydride $\left(\mathrm{NaBH}_{3} \mathrm{CN}\right)$, among other hydrides, is the reagent most employed for reductive amination: ${ }^{4}$ it is highly selective, soluble in many solvents, and stable in acid medium (up to $\mathrm{pH} 2$ ). ${ }^{1}$ Cases et al. ${ }^{5}$ found that the optimum $\mathrm{pH}$ for the reductive aminations of galactose and 1-amino-2-propanol was 4. Nevertheless, $\mathrm{NaBH}_{3} \mathrm{CN}$ generates highly toxic products such as $\mathrm{HCN}$ or $\mathrm{NaCN}$ during the reaction or work-up, and thus should not be recommended for medium or large scale reactions, and even less in the actual context of "green chemistry". Sodium triacetoxyborohydride $\left(\mathrm{NaBH}_{3}(\mathrm{OAc})\right)^{6}$ has also been employed, but mostly in non-protic solvents, since in methanol or water it reduces the carbonyl groups, decomposes, and gives flammable subproducts. ${ }^{7}$ Pyridine borane $\left(\mathrm{Pyr}-\mathrm{BH}_{3}\right)^{8-10}$ was the most representative aminoborane employed, but it is unstable, and decomposes causing fire; even explosions were reported. ${ }^{11}$

Following an initial finding of Oshima and coworkers, ${ }^{12}$ we have developed in our lab a technique for the chromatographic resolution of enantiomeric sugars by reductive amination with chiral amines (i.e. by generation of diastereomers), using $\mathrm{NaBH}_{3} \mathrm{CN}$ as the reducing agent. ${ }^{5,13}$ However, we decided now to try another less toxic reductant: the substitute chosen was the $\alpha$ picoline borane (Pic-BH $\mathbf{B H}_{3}$, Scheme 2). This reagent appeared on the market in 2004. ${ }^{11}$ Sato et al. showed its smooth working conditions in different solvents (including water), no generation of toxic wastes, stability up to $150^{\circ} \mathrm{C}$, high selectivity and low cost. ${ }^{11}$ The use of water in the reaction medium would be a remarkable advantage, especially at an industrial level.

Herein, we introduce the use of $\alpha$-picoline borane as a replacement of sodium cyanoborohydride in the reductive amination employed for the determination of the absolute configuration of the monosaccharides present in polysaccharides or glycosides, and its extension to the synthesis of aminodeoxyalditols in larger amounts. 


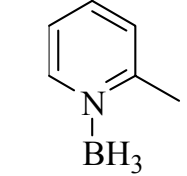

$a$-Picoline borane

$\mathrm{Pic}_{-\mathrm{BH}_{3}}$

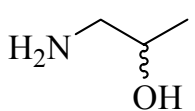

( \pm )-1-Amino-2-propanol

AP

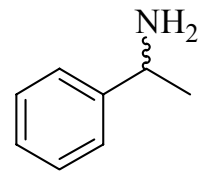

( \pm )- $a$-Methylbenzylamine

MBA

Scheme 2. Main reagents used in this work and their acronyms.

\section{Results and Discussion}

In order to evaluate the viability of the usage of $\alpha$-picoline borane (Pic-BH $\mathbf{B}$ ) instead of sodium cyanoborohydride for the reductive amination used in the determination of the absolute configuration of monosaccharides, ${ }^{5}$ it was first decided to try the reaction of D-galactose and a) $( \pm$ )-1-amino-2 propanol (AP), and b) ( \pm )- $\alpha$-methylbenzylamine (MBA, Scheme 2$)$, using the reaction conditions described by Sato et al., ${ }^{11}$ i.e. 1:1:1.2 ratio of sugar, amine and reducing agent, both in water and methanol (containing $10 \%$ of $\mathrm{AcOH}$ ). In order to follow the reaction by gas chromatography (GC), the reaction mixture was treated with acetic anhydride/ pyridine. In this way, a mixture of peracetylated aminodeoxyalditols, peracetylated galactitol and cyclic forms of penta- $O$-acetyl-D-galactose was obtained. In water, after $2 \mathrm{~h}$ only $10 \%$ of the reaction product (aminodeoxyalditol) was obtained with AP, and 1\% with MBA. The remainder was mostly galactose, with small amounts of galactitol. The methanolic reagent showed no improvement in the reaction with MBA but with AP a 74\% of diastereomeric aminodeoxyalditols were obtained, together with $20 \%$ of galactose and $5 \%$ of galactitol. These results suggested that changing the reaction conditions, the yields of aminodeoxyalditols can be improved. They also show that the reductant hardly reacted with the aldehyde group of the monosaccharide to give the corresponding alditol.

Subsequently we decided to modify the reaction with $\mathbf{P i c}-\mathbf{B H}_{\mathbf{3}}$ to the conditions used when reducing with $\mathrm{NaCNBH}_{3}{ }^{5,13}$ The reaction occurs efficiently (Table 1) with $\mathbf{A P}$ and either reducing agent (yields $>90 \%$ ). The reaction of $\mathbf{M B A}$ and $\mathbf{P i c}-\mathbf{B H} \mathbf{H}_{\mathbf{3}}$ showed the appearance of a small but significant amount of unreacted galactose. The galactose/AP diastereomers appeared in an equimolar ratio, whereas those with MBA presented stereoselectivity, as already reported. , $^{13}$ The most interesting fact was, however, the appearance of a minor peak with MBA (a resolved pair with AP) after the reaction with $\mathbf{P i c}-\mathbf{B H}_{3}$ which was absent when working with $\mathrm{NaCNBH}_{3}$. The analysis of those peaks by GC/MS revealed that they were also peracetylated 1-amino-1deoxyalditols, but (as they had different retention time) becoming from a different hexose. After discarding the presence of impurities in the Gal standard, we thought that a transposition of the double bond of the imine towards the $\mathrm{C} 1-\mathrm{C} 2$ hexose bond might occur, thus originating a loss of the $\mathrm{C} 2$ chirality. When this chirality is regenerated, it occurs with partial epimerization. 
On the first step of the reaction, the carbonyl and the amino group build reversibly an imine which can, after enolization towards $\mathrm{C} 1-\mathrm{C} 2$ of the sugar, generate a 1-amino-1-deoxyketose. ${ }^{14-17}$ This reaction is known as Amadori rearrangement (Scheme 3). In the current reductive amination reaction, if a fraction of the imine transposes the double bond by the Amadori rearrangement (Scheme 3), this alkylaminodeoxyketose can (in the presence of more reductant) generate the epimeric 1-alkylamino-1-deoxyalditols by two different pathways (Scheme 4): a) direct reduction of the ketose, generating a $\mathrm{C} 2$ stereocenter with two possible configurations, and $\mathrm{b}$ ) tautomerization of the double bond back to $\mathrm{C} 1$ to generate two epimeric imines, which are reduced to two different 1-alkylamino-1-deoxyalditols.

Table 1. Product ratio ${ }^{\mathrm{a}}$ after reductive amination between D-Gal and racemic AP or MBA using two different reducing agents

\begin{tabular}{|c|c|c|c|c|c|}
\hline \multirow[t]{3}{*}{ Conditions/ Reagents ${ }^{\mathrm{b}}$} & \multicolumn{5}{|c|}{ Molar ratio (\%) } \\
\hline & \multirow[t]{2}{*}{ D-Gal } & \multirow[t]{2}{*}{ Galactitol } & \multirow[t]{2}{*}{ "Unknown" } & \multicolumn{2}{|c|}{ Aminogalactitol } \\
\hline & & & & $\mathrm{D} /(S)$ & $\mathrm{D} /(R)=\mathrm{L} /(S)^{\mathrm{b}}$ \\
\hline $\begin{array}{c}\text { Pic-BH } \\
\text { MeOH:AcOH }(10: 1)-1 \text { h- } 65^{\circ} \mathrm{C}\end{array}$ & & & & & \\
\hline $\mathrm{D}-\mathrm{Gal}+\mathbf{A P} 1: 5$ & - & 2.3 & $4.9^{\mathrm{c}}$ & 46.6 & 46.2 \\
\hline $\begin{array}{c}\text { D-Gal + MBA 1:5 } \\
\text { NaCNBH }_{3} \\
\text { MeOH:AcOH }(13: 1)-1 \text { h- } 65{ }^{\circ} \mathrm{C}\end{array}$ & 8.3 & 3.3 & $2.3^{\mathrm{d}}$ & 51.6 & 34.4 \\
\hline D-Gal + AP 1:5 & 1.3 & 2.9 & - & 48.8 & 47.0 \\
\hline D-Gal + MBA 1:5 & 2.0 & 6.0 & - & 58.0 & 34.0 \\
\hline
\end{tabular}

${ }^{a}$ Determined by GC after acetylation. The reaction was carried out with a molar ratio Pic$\mathbf{B H}_{3} / \mathrm{Gal}$ of $1.2 .{ }^{\mathrm{b}} \mathrm{D} /(R)=\mathrm{L} /(S)$ are enantiomers chromatographically equivalent. ${ }^{\mathrm{c}}$ Two equimolar peaks with relative retention times of $0.992 .{ }^{\mathrm{d}}$ Only one peak.

Thus, if this explanation holds, partial or total epimerization of $\mathrm{C} 2$ can occur. In this case, Dgalactose would originate galactose and talose aminodeoxyalditol derivatives by a combination of reactions summarized in Scheme 5. Even though the Amadori product is built from successive reversible steps $\left(\mathrm{K}_{1}+\mathrm{K}_{3}\right)$, previous studies showed that the regeneration of the imine is very slow $\left(\mathrm{K}_{5}\right)$, especially if those products are stabilized by formation of the corresponding cyclic ketal. ${ }^{17}$ Therefore, it is most likely to obtain the epimers in $\mathrm{C} 2$ by direct reduction of the 1-amino-1deoxy-2-ketoses (Scheme 5, $\mathrm{K}_{4}$ ). However, this can only happen if $\mathbf{P i c}-\mathbf{B H}_{\mathbf{3}}$ has reducing power over ketones. This activity was reported for other aminoboranes, ${ }^{7}$ but not for $\mathbf{P i c}-\mathbf{B H}_{\mathbf{3}}$. Therefore, we have carried out an experiment to determine whether the $\mathbf{P i c}-\mathbf{B H}_{3}$ could reduce D- 
fructose. Using reaction conditions similar to those used for reductive amination, it was observed, by gas chromatography, that nearly half the fructose was reduce to mannitol and galactitol, suggesting that the $\mathrm{K}_{4}$ step (Scheme 5) is possible with this reductant.
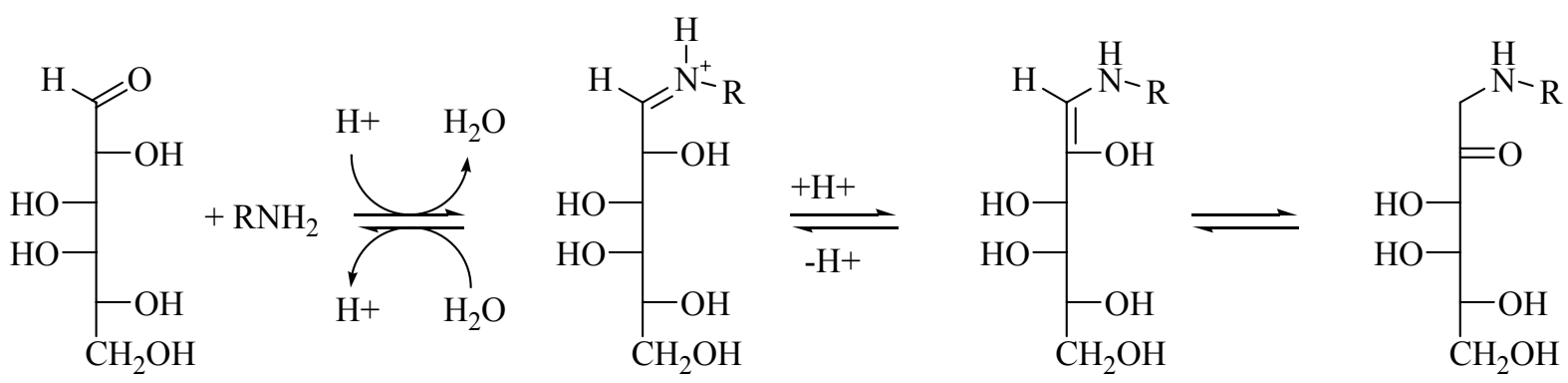

Scheme 3. Amadori rearrangement (exemplified for D-Gal and a generic amine).

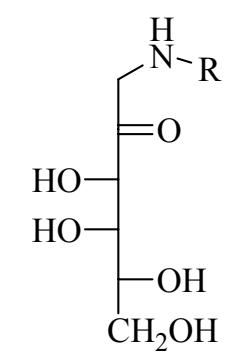

1-alkylamino-1deoxy-D-tagatose
[H]
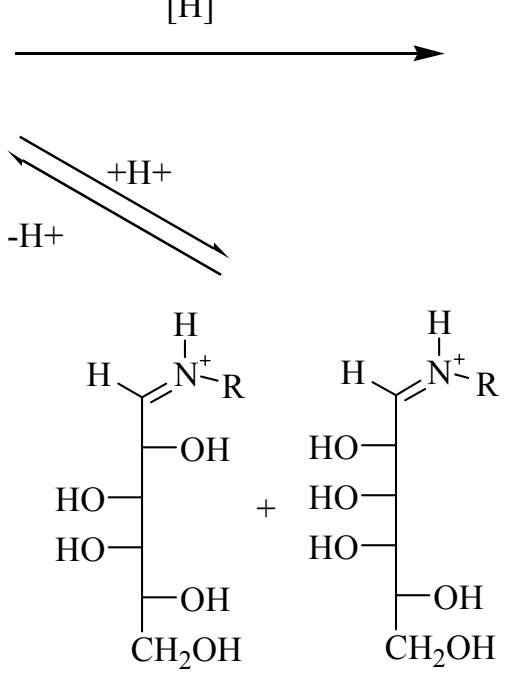
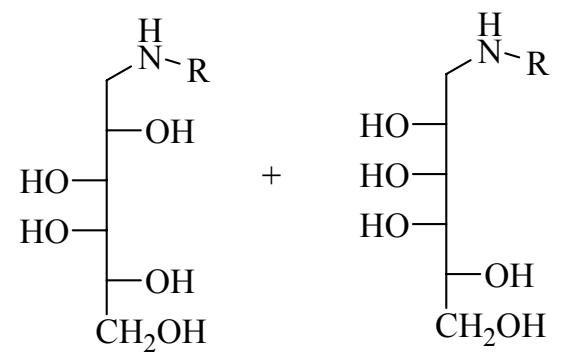

1-alkylamino-1deoxy-D-talitol

Scheme 4. Possible reduction pathways of a 1-alkylamino-1-deoxyketose.

In order to confirm the hypothesis that the unknown peaks became from epimerization of the galactose, we decided to carry out the reductive amination reaction using commercial D-talose (i.e. the $\mathrm{C} 2$ epimer of D-galactose) and $\mathbf{P i c}-\mathrm{BH}_{3}$ as reductant. $\mathrm{By} \mathrm{GC}$ of the peracetylated derivatives made with racemic AP, we were able to observe the separation of the two diastereomers, whose retention times agree with those determined for the unknown 1-amino-1deoxyhexoses peaks found in the original reaction with galactose (Table 1). With chiral AP, we have determined that the talose isomer that eluted with a lower retention time corresponded to the D-Tal/(S)-amine adduct. Minor peaks corresponding to the galactose derivative appeared, proving that the partial epimerization of the talose into the galactose was also occurring. 
The diastereomers made from racemic $\alpha$-methylbenzylamine (MBA) and D-talose could not be separated by gas chromatography under the conditions used for these derivatives (Table 1). Only one peak appears with a retention time matching (as expected) the minor peak found when analyzing the 1-deoxy-1-(1'-phenylethylamino)-galactitol.

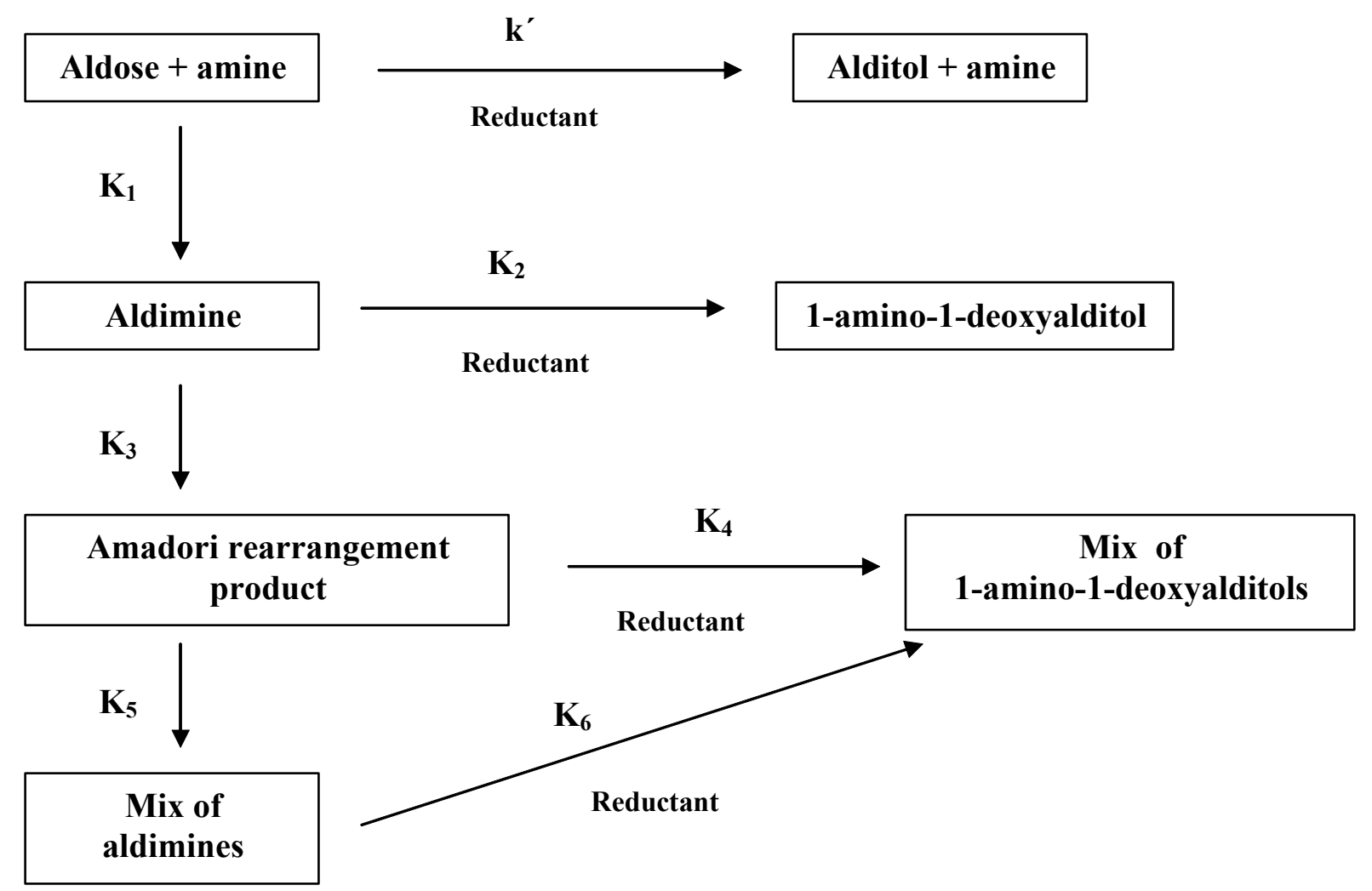

Scheme 5. Possible reaction pathways between an aldose and an amine in presence of a reductant.

These facts showed that our hypothesis was correct: there was a generation of talose derivatives as secondary products in the reactions with galactose, coming from the epimerization of $\mathrm{C} 2$ mediated by Amadori rearrangement.

The Pic- $\mathbf{B H}_{3}$ reductive amination was attempted with rhamnose and quinovose, other two $\mathrm{C} 2$ epimers which are commercially available. Once again, we were able to observe, when derivatizing each one separately with chiral $\mathbf{A P}$, the corresponding interconversion. In the case of the reaction with quinovose, the epimerization was especially important, since $c a .21 \%$ of the original monosaccharide was transformed into the rhamnose derivative (as determined by GC). Assuming that the reduction is not diastereoselective, this implies that $c a .40 \%$ of the imine of quinovose rearranged to the Amadori product. This result shows that it is not possible to predict the proportion of epimerization in the reduction reaction. 
From these results, we can conclude that $\mathrm{NaCNBH}_{3}$ probably reduces the imine groups at a higher rate than $\mathbf{P i c}-\mathbf{B H}_{3}\left(\mathrm{~K}_{2}\right)$, since the Amadori rearrangement products are absent with the former reductant (Table 1).

\section{Optimization of the reaction conditions}

The epimerization reaction is undesirable for a quantitative assessment of the monosaccharides present in a mixture. ${ }^{5,13}$ Thus, in order to be able to use $\mathbf{P i c}-\mathbf{B H} \mathbf{H}_{\mathbf{3}}$ as a safe replacement for $\mathrm{NaCNBH}_{3}$, this epimerization has to be avoided.

Using D-galactose and $\mathbf{A P}$ as the reagents, we have carried out a systematic study of the influence of several factors on the outcome of the reaction (Table 2). In the presence of AcOH, no major influence of time and temperature were found, although a small rise of the epimerization product was found as time and temperature increased (Table 2). The best results were obtained at $40^{\circ} \mathrm{C}$ and $1 \mathrm{~h}$ of reaction, though a small proportion of epimerized products still appeared. Considering that the other sugars like quinovose yield even more epimerization, the search for new reaction conditions was continued. The reductant amounts were also varied, both at $40{ }^{\circ} \mathrm{C}$ and at $65^{\circ} \mathrm{C}$ (Table 2). The results showed that at either temperature, the amount of reductant did not have any influence on the proportion of 1-amino-1-deoxytalitol. However, at $40^{\circ} \mathrm{C}$, in presence of a great excess of $\mathbf{P i c}-\mathbf{B H}_{3}$, the amount of galactitol increased, confirming the capacity of the reagent to reduce the carbonyl group, although at a slower rate ( $\left.k^{\prime}\right)$ than those of the formation and reduction of the imine $\left(\mathrm{K}_{1}\right.$ and $\mathrm{K}_{2}$, Scheme 5). Thus the reductant has an appreciable selectivity.

The key factor was acetic acid: its absence yields no epimerization at all (Table 2). These results agree with older studies of Amadori rearrangement. ${ }^{14}$ The reaction was repeated with others sugars in absence of acid catalysis, showing that no epimerization occurred in any case. These results show that $\mathbf{P i c}-\mathbf{B H}_{3}$ can be used as a reductant in the technique of enantiomeric determination of monosaccharides, ${ }^{5}$ provided that it is carried out in absence of acid to avoid isomerizations. This differs from the reductive amination with $\mathrm{NaCNBH}_{3}$, which requires acid. ${ }^{5}$

Table 3 shows the yields of the reaction (by GC, as compared with an internal standard of peracetylated inositol) using $\mathrm{NaCNBH}_{3}$ or $\mathbf{P i c}-\mathbf{B H}_{3}$, as well as modifying other reaction factors, now without acid addition. 
Table 2. Product ratios ${ }^{\mathrm{a}}$ obtained after reductive amination between D-Gal and racemic AP with Pic-BH $\mathbf{B H}_{3}$ using different reaction conditions

\section{Conditions/ Reagents}

Effect of time of reaction

$0.5 \mathrm{~h}$

$1 \mathrm{~h}$

$2 \mathrm{~h}$

$3 \mathrm{~h}$
1.4

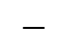

$-$

$-$

Effect of temp. of reaction ${ }^{\mathrm{e}}$

$\begin{array}{lcccc}40{ }^{\circ} \mathrm{C} & \text { tr. } & 2.9 & 1.0 & 96.1 \\ 50^{\circ} \mathrm{C} & 1.5 & 2.5 & 2.5 & 93.4 \\ 65^{\circ} \mathrm{C} & - & 2.3 & 4.9 & 92.8\end{array}$

Effect of $\mathrm{Pic}-\mathrm{BH}_{3} / \mathrm{Gal}$ ratio

$0.5: 1^{\mathrm{f}}$
$1.2: 1^{\mathrm{f}}$
$2.0: 1^{\mathrm{f}}$
$1.2: 1^{\mathrm{g}}$
$10: 1^{\mathrm{g}}$

Effect of the solvent ${ }^{\mathrm{h}}$

$\mathrm{MeOH}$
$\mathrm{MeOH}: \mathrm{AcOH}(13: 1)$

$\mathrm{MeOH}: \mathrm{AcOH}(4: 1)$
2.5

2.7

5.2

4.9

5.9

1.0

1.1

2.2

2.3

tr.

2.9

tr.

8.4
92.0

92.8

93.0

93.2
89.5

96.1

2.0

2.0

$-$

96.0

$-\quad 2.3$

4.9

92.8

1.6

4.4

3.2

90.6

$\mathrm{Gal}^{\mathrm{b}}$

${ }^{\mathrm{a}}$ Determined by gas chromatography after acetylation. ${ }^{\mathrm{b}}$ Diastereomers $\mathrm{D} /(S)+(\mathrm{D} /(R)=\mathrm{L} /(S)) .{ }^{\mathrm{c}}$ MeOH:AcOH 13:1, $65^{\circ} \mathrm{C}, 1.2$ mols of $\mathbf{P i c}-\mathbf{B H}_{3}$ and 5 mols of AP per mol of D-Gal. ${ }^{\mathrm{d}}$ Traces, percentage less than 1\%. ${ }^{\mathrm{e}} \mathrm{MeOH}: \mathrm{AcOH}$ 13:1, $1 \mathrm{~h}, 1.2$ mols of $\mathbf{P i c}-\mathbf{B H}_{\mathbf{3}}$ and 5 mols of $\mathbf{A P}$ per mol of D-Gal. ${ }^{\mathrm{f}} \mathrm{MeOH}$ :AcOH 13:1, $1 \mathrm{~h}, 65^{\circ} \mathrm{C}, 5$ mols of AP per mol of D-Gal. ${ }^{\mathrm{g}} \mathrm{MeOH}: \mathrm{AcOH}$ 13:1, $1 \mathrm{~h}, 40^{\circ} \mathrm{C}, 5$ mols of AP per mol of D-Gal. ${ }^{\mathrm{h}}$ Reaction for $1 \mathrm{~h}$ at $65^{\circ} \mathrm{C}, 1.2$ mols of Pic$\mathbf{B H}_{3}$ and 5 mols of AP per mol of D-Gal 
Table 3. Product ratios ${ }^{\mathrm{a}}$ and yields obtained after reductive amination ${ }^{\mathrm{b}}$ between $\mathrm{D}-\mathrm{Gal}$ and racemic AP using different reaction conditions

\begin{tabular}{|c|c|c|c|c|c|}
\hline \multirow[t]{3}{*}{ Conditions/ Reagents } & \multicolumn{4}{|c|}{ Molar ratio (\%) } & \multirow[t]{3}{*}{ Yield (\%) } \\
\hline & \multirow[t]{2}{*}{ Galactose } & \multirow[t]{2}{*}{ Galactitol } & \multicolumn{2}{|c|}{ Aminogalactitol } & \\
\hline & & & $\mathrm{D} /(S)$ & $\mathrm{D} /(R)=\mathrm{L} /(S)^{\mathrm{c}}$ & \\
\hline \multicolumn{6}{|l|}{$\mathrm{NaCNBH}_{3}{ }^{d}$} \\
\hline D-Gal / AP 1:5 & 1.3 & 2.9 & 48.8 & 47.0 & 98 \\
\hline \multicolumn{6}{|l|}{ Pic- $\mathrm{BH}_{3}{ }^{\mathrm{d}}$} \\
\hline D-Gal / AP 1:5 & 1.8 & 2.0 & 50.0 & 46.2 & 97 \\
\hline \multicolumn{6}{|l|}{ Effect of D-Gal/AP ratio ${ }^{\mathrm{e}}$} \\
\hline $1: 1.2$ & 5.5 & 3.8 & & $90.7^{\mathrm{f}}$ & 93 \\
\hline $1: 3.0$ & 4.8 & 3.2 & & $92.0^{\mathrm{f}}$ & 94 \\
\hline $1: 5.0$ & 3.0 & - & & $97.0^{\mathrm{f}}$ & 97 \\
\hline \multicolumn{6}{|l|}{ Effect of temperature ${ }^{e}$} \\
\hline $40^{\circ} \mathrm{C}$ & 27.7 & 1.2 & & $71.1^{\mathrm{f}}$ & 77 \\
\hline $50{ }^{\circ} \mathrm{C}$ & 10.7 & 1.2 & & $88.2^{\mathrm{f}}$ & 83 \\
\hline $65^{\circ} \mathrm{C}$ & 3.0 & - & & $97.0^{\mathrm{f}}$ & 97 \\
\hline
\end{tabular}

${ }^{\mathrm{a}}$ Determined by gas chromatography after acetylation. ${ }^{\mathrm{b}}$ Molar yield taking peracetylated inositol as $100 .{ }^{c} \mathrm{D} /(R)=\mathrm{L} /(S)$ are enantiomers chromatographically equivalent. ${ }^{\mathrm{d}}$ In the reaction conditions previously determined as optimal. ${ }^{\mathrm{e}}$ With the remaining reaction conditions previously determined as optimal with Pic-BH $\mathbf{B H}_{3}{ }^{\mathrm{f}}$ Diastereomers $\mathrm{D} /(S)+(\mathrm{D} /(R)=\mathrm{L} /(S))$.

The reaction yields are almost identical for both reducing agents (Table 3). The small proportions of unreacted galactose and galactitol were also very similar for both reductants, and no epimerization was observed. The optimal amine/sugar ratio was investigated, as the earlier Pic-BH B $_{3}$ reductions ${ }^{11}$ were carried out with equimolar amounts of carbonyl compound and amine. Table 3 shows that the best yields, and the lower amounts of side-products are obtained using a five-fold excess of amine over the carbonyl compound, as expected ${ }^{1,5}$ considering that equimolar amounts might lead to reaction of the product (a secondary amine) with another carbonyl group to generate a tertiary amine. Besides, it has been shown (Table 3 ) that a higher temperature is needed to provide a complete reaction, as lower ones give rise to large amounts of unreacted monosaccharides. These results show that in optimal working conditions it is possible to use $\alpha$-picoline borane as a reducing agent instead of sodium cyanoborohydride without affecting the selectivity or the yield. 


\section{Other applications}

In order to test this modification of the technique, the configuration of the monosaccharides of the raw corallinan extracted from the red seaweed Corallina officinalis was assessed. This polysaccharides was chosen since it contains a great variety of monomethylated galactoses. ${ }^{18}$ The sugars obtained after hydrolysis and $\mathbf{P i c}-\mathbf{B H}_{3} / \mathbf{A P}$ reductive amination were D-Xyl (22\%), 2$O$-Me-Gal (5\%), 4-O-Me-D-Gal (2 \%), 4-O-Me-L-Gal (2\%), D-Glc (9\%), D-Gal (35\%) and L$\mathrm{Gal}(25 \%)$. These figures agree with the xylose-substituted agaran structure of this polymer, ${ }^{19}$ with previous reports, ${ }^{18}$ and with the results of the same sample derivatized using $\mathrm{NaCNBH}_{3}$. The configuration of the 2-O-Me-Gal cannot be determined using $\mathbf{A P} .^{5}$

The reductive amination with $\mathbf{P i c}-\mathbf{B H}_{3}$ was also tested with other amines, like $\alpha$ methylbenzylamine, propylamine, butylamine and octylamine, in methanol without $\mathrm{AcOH}$. No epimerization was found to occur in either case. The synthesis was also carried out in preparative scale using D-galactose and (S)-MBA. The isolated yield was $73 \%$ and the product was characterized by the usual spectroscopical techniques (see Experimental Section).

The reductant was also used in the determination of the configuration of 3,6anhidrogalactose, ${ }^{13}$ which requires more subtle conditions, on a commercial $\kappa$-carrageenan (which ideally contains similar amounts of D-Gal and 3,6-An-D-Gal). MBA was used as the chiral amine. Both the reactions with $\mathrm{NaCNBH}_{3}$ and $\mathbf{P i c}-\mathbf{B H}_{3}$ (each in its optimal conditions) show negligible amounts of alditols or unreacted galactose. The yields relative to inositol were 84 and $80 \%$, respectively. The difference is quite small, although observable in other experiences with MBA. Both reductants showed a slight excess of 3,6-AnGal over Gal.

\section{Conclusions}

The current results show that $\alpha$-picoline borane can be used for the technique of configurational determination of sugars as a safe replacement of $\mathrm{NaCNBH}_{3}$, without affecting the results. This new modification assures lower toxicity, and thus a more environmental-friendly reaction practice in the context of green chemistry.

The reactions conditions use for $\alpha$-picoline borane in the reductive amination reaction of monosaccharides were modified in comparison to those employed for $\mathrm{NaCNBH}_{3}$. The main reason for the modification was that, in the presence of acetic acid, secondary epimeric products were produced due to an Amadori rearrangement.

The yields of the reductive amination reactions with $\alpha$-picoline borane in methanol without acid are comparable to those obtained with $\mathrm{NaCNBH}_{3}$, either in a monosaccharide standard system, or for the analysis of polysaccharides. Preparative synthesis is also possible with good yields of isolated product. 


\section{Experimental Section}

Reagents and solvents. The $\alpha$-picoline borane (Pic-BH $\mathbf{B H}_{3}$ was purchased from Junsei Chemical Co., Japan and from Sigma-Aldrich. All the remaining reagents, standards and solvents were of analytical grade, and were purchased in Sigma-Aldrich, Fluka, or Merck. The sample of commercial $\kappa$-carrageenan was purchased from Sigma.

\section{Reductive amination of galactose}

The preliminary experiments were carried out using either the procedure of Sato et al. ${ }^{11}$ (Method A) or Cases et al. ${ }^{5}$ (Method B). The amines tested were ( \pm ) 1-amino-2-propanol (AP) and ( \pm )- $\alpha$ methylbenzylamine (MBA). The products were always analyzed by gas chromatography as peracetylated aminoalditols, using the chromatographic conditions shown later. ${ }^{5}$

Method A. $0.027 \mathrm{mmol}$ ( $5 \mathrm{mg}$ ) of D-Gal and $0.027 \mathrm{mmol}(5 \mathrm{mg})$ of inositol (internal standard) were added into $150 \mu \mathrm{l}$ of a mixture of $\mathrm{H}_{2} \mathrm{O}-\mathrm{AcOH} 10: 1$. Then, $0.027 \mathrm{mmol}$ of amine and 0.027 mmol (2.89 mg) of Pic- $\mathbf{B H}_{3}$ were added. The mixture was stirred for $2 \mathrm{~h}$ at room temperature and then it was acidified with TFA $3 \mathrm{M}$. The solution was evaporated off, washed with water $(3 \mathrm{x}$ $0.5 \mathrm{ml}$ ) and the residue left on a vacuum desiccator overnight. Then, the residue was acetylated by adding $1 \mathrm{ml}$ of a mixture of $\mathrm{Ac}_{2} \mathrm{O}-\mathrm{Pyr}(1: 1)$ for $45 \mathrm{~min}$ at $100^{\circ} \mathrm{C}$. Once the solution cooled down, it was extracted with $\mathrm{CHCl}_{3} / \mathrm{H}_{2} \mathrm{O}$. The aqueous phase was reextracted with $\mathrm{CHCl}_{3}$. The organic extracts were joined and washed with $1 \mathrm{ml}$ of satd $\mathrm{NaHCO}_{3}$ sn (x 3) and with $1 \mathrm{ml}$ of water (x 2). Finally, the organic phase was dried with $\mathrm{Na}_{2} \mathrm{SO}_{4}$ (anh.) and evaporated off. The residue was redissolved in $\mathrm{CHCl}_{3}$ to inject into the gas chromatograph apparatus. The same procedure was carried out using a $\mathrm{MeOH} / \mathrm{AcOH}$ 10:1 mixture as solvent.

Method B. The reductive amination was carried out with $0.006 \mathrm{mmol}(1 \mathrm{mg})$ of D-Gal as described by Cases et al. ${ }^{5}$, but using $\mathbf{P i c}-\mathbf{B H}_{3}$ as reductant and adding $0.006 \mathrm{mmol}$ (1 mg) of inositol as an internal standard. We added to the vial consecutively: 20 or $32 \mu 1$ of a solution 1:8 (v/v) of AP or MBA, respectively, in $\mathrm{MeOH}$ ( 5 mols amine/mol Gal), $17 \mu \mathrm{l}$ of a $\mathrm{AcOH} / \mathrm{MeOH}$ solution 1:4 (v/v) and $13 \mu \mathrm{l}$ of $\mathbf{P i c}-\mathbf{B H}_{3} 5 \%(\mathrm{w} / \mathrm{v})$ in $\mathrm{MeOH}$ (1.2 mols reductant $\left./ \mathrm{mol} \mathrm{Gal}\right)$. The reaction was heated at $65^{\circ} \mathrm{C}$ for $1 \mathrm{~h}$, allowed to cool down, and acidified with TFA 3M up to $\mathrm{pH}$ 1-2. The remaining work up was carried out as depicted for the method A.

Study of the reactions conditions using $\alpha$-picoline borane. This set of reactions was carried out with D-Gal and AP, using the method B modified in order to test for different temperatures $\left(40-65^{\circ} \mathrm{C}\right)$, reaction times $(0.5-3 \mathrm{~h})$, reducing agent proportions ( $0.5-2$ equivalents), proportion of $\mathrm{AcOH}$ and amine, etc.

Optimized conditions for the reductive amination with $\alpha$-picoline borane. To $0.027 \mathrm{mmol}$ ( 5 $\mathrm{mg}$ ) of reducing sugar it was consecutively added: $50 \mu \mathrm{l}$ of $\mathrm{MeOH}, 0.135 \mathrm{mmols}$ of amine and $0.03 \mathrm{mmol}(3.21 \mathrm{mg})$ of $\mathbf{P i c}-\mathbf{B H}_{3}$, and the mixture was heated at $65^{\circ} \mathrm{C}$ in a closed vial for $1 \mathrm{~h}$. After cooling down, drops of TFA 3M were added up to $\mathrm{pH} 1-2$. The solutions were dried, washed with water $(3 \times 0.5 \mathrm{ml})$ and with $\mathrm{MeOH}(5 \times 0.5 \mathrm{ml})$. The residue was left on a vacuum desiccator with overnight, and then the products were acetylated and worked up as described in Method A. 
Reduction of fructose. Fructose was submitted to the conditions described in Method B, but without adding the amine.

Analysis of polysaccharides. The polysaccharide from Corallina officinalis ${ }^{18}$ was hydrolyzed with $2 \mathrm{M}$ TFA (90 min, $120^{\circ} \mathrm{C}$ ) before analysis of the corresponding monosaccharides, whereas the $\kappa$-carrageenan was submitted to a reductive hydrolysis as described by Navarro and Stortz, ${ }^{13}$ but using Pic-BH $\mathbf{B H}_{3}$ instead of $\mathrm{NaCNBH}_{3}$.

Gas-liquid chromatography. It was carried out in a Hewlett Packard 5890A Apparatus equipped with a flame ionization detector (FID) and a HP 3395 integrator. The carrier gas was $\mathrm{N}_{2}(0.8 \mathrm{ml} / \mathrm{min})$ and the split relation was close to $80: 1$. The injector and detector temperature were set to $270{ }^{\circ} \mathrm{C}$. The products from the reductive amination were analyzed with an Ultra 2 column (Hewlett-Packard, $50 \mathrm{~m}, 0.36 \mathrm{~mm}$ i.d., $0.17 \mu \mathrm{m}$ film width). For peracetylated 1-deoxy-1(2'-hydroxypropylamino)alditols the program ramp was programmed from 180 to $220{ }^{\circ} \mathrm{C}$ at 4 ${ }^{\circ} \mathrm{C} / \mathrm{min}$, hold at $220^{\circ} \mathrm{C}$ for $2 \mathrm{~min}$, from 220 to $250{ }^{\circ} \mathrm{C}$ at $1{ }^{\circ} \mathrm{C} / \mathrm{min}$, then hold at $250{ }^{\circ} \mathrm{C}$ for $20 \mathrm{~min}$. For peracetylated 1-deoxy-1-(2'phenylethylamino)alditols the program started from 180 to 220 ${ }^{\circ} \mathrm{C}$ at $4{ }^{\circ} \mathrm{C} / \mathrm{min}$, hold at $220^{\circ} \mathrm{C}$ for $2 \mathrm{~min}$, from 220 to $270^{\circ} \mathrm{C}$ at $1{ }^{\circ} \mathrm{C} / \mathrm{min}$, and hold at $270{ }^{\circ} \mathrm{C}$ for $20 \mathrm{~min}$.

Synthesis of (S)-1-deoxy-1-(1'-phenylethylamino)-D-galactitol. To a solution of $0.33 \mathrm{mmol}$ $(60 \mathrm{mg})$ of D-Gal in $4 \mathrm{ml}$ of $\mathrm{MeOH}, 214 \mu \mathrm{l}$ of $(S)$ - $\alpha$-methylbenzylamine $(5$ mols amine/mol Gal) and $39 \mathrm{mg}$ of $\mathbf{P i c}-\mathbf{B H}_{3}$ (1.25 mols reductant $\left./ \mathrm{mol} \mathrm{Gal}\right)$ were added. The reaction mixture was heated at $65{ }^{\circ} \mathrm{C}$ for $3 \mathrm{~h}$. The solvent was removed under reduced pressure. The product was purified using an Amberlite IR-120 $\left(\mathrm{H}^{+}\right)$column: after washing with $75 \mathrm{ml}$ water, the product was eluted with $75 \mathrm{ml}$ of $1 \mathrm{M} \mathrm{NH}$. After exhaustive perevaporation at reduced pressure, the sample was obtained as a white solid by freeze-drying. Yield 73\% (69.3 mg), decomposes at 209-2 $11^{\circ} \mathrm{C} .{ }^{1} \mathrm{H}$ NMR $\left(500.1 \mathrm{MHz}, \mathrm{D}_{2} \mathrm{O}+1\right.$ drop $\left.\mathrm{HCl}\right): \delta_{\mathrm{H}} 1.29\left(3 \mathrm{H}, \mathrm{d}, J_{1^{\prime}, 2^{\prime}}=6.6 \mathrm{~Hz}, \mathrm{CH}_{3}\right), 2.49$ $\left(1 \mathrm{H}, \mathrm{dd}, J_{1 \mathrm{a}, 2}=4.1 \mathrm{~Hz}, J_{1 \mathrm{a}, 1 \mathrm{~b}}=12.6 \mathrm{~Hz}, \mathrm{H1a}\right), 2.53\left(1 \mathrm{H}, \mathrm{dd}, J_{1 \mathrm{~b}, 2}=8.3 \mathrm{~Hz}, J_{1 \mathrm{a}, 1 \mathrm{~b}}=12.6, \mathrm{H} 1 \mathrm{~b}\right)$, $3.39\left(1 \mathrm{H}, \mathrm{dd}, J_{2,3}=\right.$ ca. $\left.1 \mathrm{~Hz}, J_{3,4}=9.3 \mathrm{~Hz}, \mathrm{H} 3\right), 3.50\left(1 \mathrm{H}, \mathrm{dd}, J_{3,4}=9.3 \mathrm{~Hz}, J_{4,5}=\right.$ ca. $\left.1 \mathrm{~Hz}, \mathrm{H} 4\right)$, $3.55\left(2 \mathrm{H}, \mathrm{d}, J_{5,6}=6.4 \mathrm{~Hz}, \mathrm{H} 6 \mathrm{a} \& \mathrm{H} 6 \mathrm{~b}\right), 3.78\left(1 \mathrm{H}, \mathrm{q}, J_{1}, 2^{\prime}=6.6 \mathrm{~Hz}, \underline{\mathrm{HCPh}}\right), 3.81\left(1 \mathrm{H}, \mathrm{dt}, J_{4,5}=\mathrm{ca}\right.$. $\left.1 \mathrm{~Hz}, J_{5,6}=6.4 \mathrm{~Hz}, \mathrm{H} 5\right), 3.90\left(1 \mathrm{H}, \mathrm{ddd}, J_{1 \mathrm{a}, 2}=4.2 \mathrm{~Hz}, J_{1 \mathrm{~b}, 2}=8.3 \mathrm{~Hz}, J_{2,3}=\mathrm{ca} .1 \mathrm{~Hz}, \mathrm{H} 2\right), 7.22-$ $7.36\left(5 \mathrm{H}, \mathrm{m}\right.$, Aromatic H). ${ }^{13} \mathrm{C}$ NMR $\left(125.8 \mathrm{MHz}, \mathrm{D}_{2} \mathrm{O}+1\right.$ drop $\mathrm{HCl}$, from HSQC spectrum): $\delta_{\mathrm{C}}$ $22.0\left(\mathrm{CH}_{3}\right), 49.4$ (C1), 57.0 (태Ph), 63.1 (C6), 68.2 (C2), 69.4 (C4), 70.1 (C5), 71.0 (C3), 126.8, 127.5 and 128.8 (Aromatic C). HRMS (ESI): Calcd. for $\mathrm{C}_{14} \mathrm{H}_{24} \mathrm{NO}_{5}: \mathrm{m} / \mathrm{z} 286.16490$; found : $\mathrm{m} / z$ 286.16585 .

\section{Acknowledgements}

The authors are indebted to Dr. R. Erra Balsells for setting up the first purchase of $\alpha$-picoline borane in Japan, and to Dr. E. A. Rúveda (IQUIOS-UNR) for helpful discussions. V.A.C. has a fellowship from the University of Buenos Aires, whereas D.A.N. and C.A.S. are Research 
Members of the National Research Council of Argentina (CONICET). This work was supported by grants from UBA (X-214) and CONICET (PIP 5699 and 0559/10).

\section{References}

1. Borch, R. F.; Bernstein, M. D.; Durst, H. D. J. Am. Chem. Soc. 1971, 93, 2897.

2. March, J. Advanced Organic Chemistry, 4th Edn., Wiley-Interscience Publication: New York. 1992; p 1495.

3. Hayes, K. S. Appl. Cat. A. 2001, 187.

4. Lane, C. F. Synthesis. 1975, 135.

5. Cases, M. R.; Cerezo, A. S.; Stortz, C. A. Carbohydr. Res. 1995, 269, 333.

6. Abdel-Magid, A. F.; Carson, K. G.; Harris, B. D.; Maryanoff, C. A.; Shah, R. D. J. Org. Chem. 1996, 61, 3849.

7. Heydari, A.; Khaksar, S.; Akbari, J; Esfandyari, M.; Pourayoubi, M.; Tajbakhsh, M. Tetrahedron Lett. 2007, 1135.

8. Pelter, A.; Rosser, R. M.; Mills, S. J. Chem. Soc. Perkin Trans. 1. 1984, 717.

9. Burkhardt, E. R.; Matos, K. Chem. Rev. 2006, 106, 2617.

10. Moormann, A. E. Synth. Comm. 1993, 23, 789.

11. Sato, S; Sakamoto, T.; Miyazawa, E.; Kikugawa, Y. Tetrahedron. 2004, 60, 7899.

12. (a) Oshima, R.; Kumanotani, J. Chem. Lett. 1981, 943. (b) Oshima, R.; Kumanotani, J. J. Chromatogr. 1983, 259, 159.

13. Navarro, D.A.; Stortz, C.A. Carbohydr. Res. 2003, 338, 2111.

14. Hodge, J. E. Adv. Carbohydr. Chem. 1955, 10, 169.

15. Hodge, J. E.; Rist, C. E. J. Am. Chem. Soc. 1953, 75, 316-322.

16. Oliver, C. M.; Melton, L. D.; Stanley, R. A. Crit. Rev. Food Sci. Nutr. 2006, 46, 337.

17. Yaylayan, V. A.; Huyghues-Despointes, A. Crit. Rev. Food Sci. Nutr. 1994, 34, 321.

18. Cases, M. R.; Stortz, C. A.; Cerezo, A. S. Phytochemistry. 1992, 31, 3897.

19. Cases, M. R.; Stortz, C. A.; Cerezo, A. S. Int. J. Biol. Macromol, 1994, 16, 93. 